\title{
Effects of Haloperidol on Responding Maintained with Food and Sucrose-Water
}

\author{
Efectos del Haloperidol sobre la respuesta mantenida \\ con comida y agua azucarada*
}

Recibido: mayo 2 de 2009 ～Revisado: octubre 6 de 2009 Aceptado: enero 14 de 2010

\author{
CARLOS F. APARICIO** \\ Savannah State University, U.S.A.
}

Para citar este artículo. Aparicio, C.F. (2010). Effects of Haloperidol on Responding Maintained with Food and Sucrose-Water. Universitas Psychologica, 9 (3), 641-661.

* Research article

** Department of Social And Behavioral Sciences. 3219 College Street, Savannah, Ga 31404, U.S.A.

E-mail: apariciocf@savannahstate.edu

\begin{abstract}
A B S T R A C T
The "hedonic" value of reinforcers is mediated by dopamine. Accordingly, haloperidol diminishes the value of reinforcers, by interfering with the emission of operant behaviors. Alternatively, the interference of dopamine transmission does not prevent animals from eating food. Thus, reinforcers remain intact after the administration of haloperidol. We assessed these possibilities with eight Wistar rats and two types of reinforcers, food-pellets and sucrose-water, delivered under multiple reinforcement schedules. In general, lever presses maintained by food-pellets were higher than those maintained by sucrose-water. Haloperidol produced dose-related decreases in lever presses and obtained reinforcers. Different doses had no effect on the number of lever presses. Subcutaneous administrations of haloperidol produced higher decreases in lever presses than intra-peritoneal administrations. Decreases in lever pressing were not necessarily accompanied by substantial reductions in obtained food-pellets and sucrose-water reinforcers; under the effects of haloperidol rats continued to produce a considerable number of both types of reinforcers.

Keywords author

Haloperidol, Anhedonia, Multiple Schedules, Food-Pellets, Sucrose-Water, Rats.

Keywords plus

Operant Behavior, Causality, Haloperidol.

\section{RESUMEN}

La dopamina es un mediador del valor "hedonico" de los reforzadores. El haloperidol reduce el valor del reforzador, interfiriendo con la emisión de conductas operantes. Alternativamente, interferencias en la transmisión de dopamina no impiden que los animales consuman el alimento. Los reforzadores quedan intactos después de la administración del haloperidol. Exploramos esas posibilidades con dos tipos de reforzadores, comida y agua azucarada, entregados en programas múltiples de reforzamiento. La comida mantuvo un mayor número de presiones de palanca que el agua-azucarada. Las presiones de palanca y los reforzadores obtenidos disminuyeron con el incremento en la dosis de haloperidol. Las diferencias en presiones de palanca entre alimento y agua-azucarada se mantuvieron con el haloperidol. La administración subcutánea del haloperidol causó mayores decrementos en las presiones de palanca que la administración intraperitoneal, pero no necesariamente causó decrementos en los reforzadores obtenidos; con el haloperidol las ratas continuaron produciendo los dos tipos de reforzadores. Palabras clave autor

Haloperidol, anhedonia, programas múltiples, comida, agua azucarada, ratas. Palabras clave descriptor

Conducta operante, causalidad, haloperidol.
\end{abstract}




\section{Introduction}

The hypothesis that dopamine antagonists (e.g., neuroleptics) induce anhedonia (Wise, Splinder, de Wit \& Gerberg, 1978) is well documented in behavioral pharmacology (Tombaugh, Tombaugh \& Anisman, 1979; Wise, 1982, 1985; Wise \& Colle, 1984). Evidence supporting the anhedonia hypothesis shows that neuroleptics suppress operant behaviors maintained by positive reinforcement (Ettenberg, 1989; Fouriezos, Hansson \&Wise, 1978; Fouriezos \& Wise, 1976; Franklin \& McCoy, 1979; Miller, Wickens \& Beninger, 1990; Wise \& Raptis, 1982). The interpretation of this result is that neuroleptics diminish the hedonic value of food reinforcers, and, thus reduce the emission of operant behaviors (Cheeta, Brooks \& Willner, 1995; Hoebel, 1988; Smith, 1995). Evidence inconsistent with this interpretation, however, comes from studies showing that decreases in food-maintained operant responding and decreases in feeding produced by neuroleptics are not necessarily the result of decreased reinforcing strength (Salamone et al., 1996; Salamone, Cousisns \& Snyder, 1997) or decreased appetite (Salamone, Arizzi, Sandoval, Cervone \& Aberman, 2002).

Neuroleptics reduce feeding efficiency (Blundell, 1987; Clifton, Rusk \& Cooper, 1991) and suppress locomotion (Pitts \& Horvitz, 2000), suggesting the effects of the drug on the motor system (Fiberger, Carter \& Phillips, 1976; Tombaugh et al., 1979). Although the effects of neuroleptics on foodreinforced behavior are not comparable to those produced by pre-feeding the organism (Salamone, Zigmond \& Strikal, 1990), neuroleptics decrease lever pressing maintained by food, Rolls et al., 1974), food consumption (Fiberger et al., 1976), and food approach (Salamone, 1996; Rusk \& Cooper, 1994). These findings indicate that dopamine modulates functions that are common to motivational and motoric control (Salamone, 1992). These constructs, however, may not describe the independent and mutually exclusive effects of neuroleptics; motivational and motoric effects of these drugs may overlap and, thus, share common brain mechanisms (Salamone, 1986, 1987, 1988, 1991).
Finding a method capable separating the effects of neuroleptics on motivational control from those on motoric control has been difficult. Aparicio (1998) proposed the barrier choice paradigm to assess the effects of neuroleptics on motivational and motoric elements of operant responding within the same experimental situation. In this methodd food became available to rats by pressing two concurrently available levers. A barrier of $15 \mathrm{~cm}$ between the levers obstructed direct passage from one lever to the other, obligating the rats to climb the barrier when traveling from one lever to the other. By raising the barrier from 15 to $76 \mathrm{~cm}$, Aparicio increased the travel distance between the lever while assessing four doses of haloperidol $(0.02,0.04,0.08$, and $0.16 \mathrm{mg} / \mathrm{kg})$ across each barrier size. He found that raising the barrier or increasing the dose of haloperidol had similar effects on choice, the rats stayed longer on one side of the chamber and made more presses on that lever producing food reinforcers. That is, haloperidol impeded climbing the barrier at doses that did not impair food maintained lever pressing (Aparicio, 1998). In additional choice studies, where the rate of food deliveries varied across two (Aparicio, 1999, 2003a) or eight (Aparicio \& Velasco, 2003) alternatives, haloperidol decreased the overall response output without affecting response allocation (interestingly, the highest doses of haloperidol produced exclusive preference for one alternative, but not necessarily the richer alternative). Similarly, haloperidol did not interfere with adaptation to rapid changes in contingencies of reinforcement (Aparicio, 2003b), nor did it affect choice controlled by different rates and amounts of reinforcers (Aparicio, 2007a). These results are not consistent with the notion that this drug causes anhedonic effects (Aparicio, 2007b).

Because of the cumulative body of evidence inconsistent with the anhedonia hypothesis, some researchers in neuroscience have focused on aspects of behavior such as vigor or persistence of work output in foraging activities, claiming: 1) that animals continually make choices based upon cost/benefit analyses, and 2) dopamine in nucleus accumbens is involved in behavioral activation, 
exertion of effort, and effort-related choices, Salamond \& Correa, 2002; Salamone et al., 1991, 1997). These ideas come from studies (Salamone, Cousing \& Bucher, 1994; Cousins, Atherton, Turner \& Salamone, 1996) showing that neuroleptics make animals less likely to respond to alternatives requiring a high cost (e.g., climb a wall and press a lever) to produce a preferred food (i.e., foodpellets), shifting preference towards an alternative requiring a low cost (e.g., sitting in the chamber) where a non-preferred food (chow) is freely available; that is, the same drugs (e.g., haloperidol, SKF 83566, or raclopride) that decrease lever pressing for high-hedonic-value reinforcers (food-pellets) increase the consumption of chow, the low-hedonic-value food, Cousins et al., 1996; Cousins, Wel \& Salamone, 1997; Cousion et al., 1996; Koch, Schmid, Schnitzler, 2000).

Other attempts to assess the hedonic value of food reinforcers within the same situation; Weatherly, Davis \& Melville, 2000; Weatherly \& Moulton, 2001; Weatherly, Rue, Davis \& Melville 2000; Weatherly, Stout, McMurry, Rue \& Melville, 1999) used multiple schedules of reinforcement with two variable interval (VI) components in sessions lasting 1 hour, in the first 30 minutes, one VI provided liquid-sucrose and in the second 30 minutes, the other VI delivered food-pellets. In these studies of lever pressing maintained by 1 or $5 \%$ of sucrose solution increased in the first VI if food-pellets, rather than the same sucrose solution, were delivered in the second VI. The interpretation of this result is that food-pellets delivered in the second half of the session represented an increase in the reinforcer value relative to either 1 or $5 \%$ liquid-sucrose obtained in the first half of the session (Weatherly; Stout, Davis \& Melville, 2001; Weatherly, Stout, Rue \& Melville, 2000, Weatherly, Moulton \& Ritt, 2002; Weatherly, Arthur \& Tischar, 2003).

The procedure described in the above studies can be used to assess the anhedonia hypothesis' claim that neuroleptics diminish the reinforcing value of food reinforcers. Accordingly, in a multiple schedule with two VI components, one VI component delivering reinforcers of relatively low hedonic value (a drop of $5 \%$ liquid-sucrose solution) and the other VI component delivering reinforcers of relatively high hedonic value (food-pellets), it would be expected that behavior maintained by the weaker reinforcer (i.e., sucrosewater) would be more sensitive to the suppressive effects of haloperidol.

Alternatively, if haloperidol does not reduce reinforcing value of food reinforcers, but it acts on the motor system by interfering with the emission of operant responses, then dose-related decreases in lever presses will occur in both VI components; so, we should expect that the behavior maintained by both potent (food-pellets) and weak (sucrosewater) reinforcers will show comparable decreases across doses of haloperidol.

In four phases using multiple schedules with two VI components, we explored the above possibilities as follows. Phase 1 determined whether the hedonic value of food-pellets was higher than that of sucrose-water reinforcers, changes in lever presses were analyzed in conditions where the rate of one reinforcer type increased in one VI component, while the rate of the other reinforcer type remained invariant in the other VI component. Phase 2 assessed the effects of intra-peritoneal administrations of haloperidol $(0.05,0.10,0.15$, and $0.20 \mathrm{mg} / \mathrm{kg}$ on reductions in the number of lever presses maintained by the high-and low-hedonic-value reinforcers (i.e., food pellets, and sucrose water, respectively). Phase 3 studied the possibility that the white noise associated with the first VI component and the white light associated with the second VI component, differed from one another in controlling different numbers of lever presses in the first and second half of the session. Thus, phase 3 reversed the order of these stimuli, the light was associated with the first VI component and the white noise was associated with the second VI component. Phase 4 assessed the possibility that subcutaneous administration of haloperidol $(0.0125,0.0250,0.0500$, and 0.0100 $\mathrm{mg} / \mathrm{kg}$ ) is more potent in decreasing lever pressing than intra-peritoneal administration of haloperidol, because subcutaneous administration is known to produce longer lasting and steadier effects on behavior than those produced by intra-peritoneal administration of haloperidol. 


\section{Method}

\section{Subjects}

Eight male experimentally naïve Wistar rats (Harlan Sprague; Dawley, IN) numbered R50 to R57, were maintained at $85 \%$ of their free body weights. The rats were approximately 90 days old when the experiment began and were housed individually with free access to water in a temperature-controlled colony room on a 12-light: 12 dark cycle.

\section{Apparatus}

Four modular chambers (Coulbourn E10-18TC) for rats measuring $310 \mathrm{~mm}$ long, $260 \mathrm{~mm}$ wide, and $320 \mathrm{~mm}$ high (inside) were enclosed in soundattenuating boxes that from the outside measured $780 \mathrm{~mm}$ wide, $540 \mathrm{~mm}$ long, and $520 \mathrm{~mm}$ high. A square metal grid constituted the floor of each chamber. A lever (E21-03), $30 \mathrm{~mm}$ wide and 15 $\mathrm{mm}$ long requiring a force of $0.2 \mathrm{~N}$ to operate, was centered on the front wall of each chamber 100 $\mathrm{mm}$ above the floor. A white $24 \mathrm{~V}$ DC light bulb (E11-03) was installed $20 \mathrm{~mm}$ above the lever. A food cup (E14-01), $30 \mathrm{~mm}$ wide and $40 \mathrm{~mm}$ long, was installed $10 \mathrm{~mm}$ from the left wall and $20 \mathrm{~mm}$ above the floor. A food dispenser (E14-24) located behind the front wall delivered 45-mg food pellets (Formula A/1 Research Diets) into the food cup. A water dipper cup containing a $0.05 \mathrm{cc}$ drop of sucrose-water $(5 \% \mathrm{w} / \mathrm{v})$ was installed $10 \mathrm{~mm}$ from the right wall and $20 \mathrm{~mm}$ above the floor. A speaker (E12-01) $26 \mathrm{~mm}$ wide by $40 \mathrm{~mm}$ high, was mounted on the front wall of each chamber $10 \mathrm{~mm}$ from the right wall and $20 \mathrm{~mm}$ from the ceiling and connected to a white noise generator (E12-08) which provided a constant white noise $20 \mathrm{kHz}(+/-3 \mathrm{~dB})$. A white $24 \mathrm{~V} \mathrm{DC}$ light bulb (E11-03), which was centered and installed on the ceiling of each chamber, provided the illumination of the chamber. All experimental events were arranged on a $\mathrm{HP} \circledR$ PC-compatible computer running Coulbourn$\mathrm{PC} \otimes$ software, located in a room remote from the experimental chamber. The computer recorded the time (10-ms resolution) at which every event occurred in experimental sessions.

\section{Procedure}

\section{Training}

The rats were randomly assigned to two groups (Group F-W and Group W-F) of four each. Rats in Groups F-W and W-F were numbered 50 to 53 and rats 54 to 57 , respectively. In sessions that lasted 30 minutes, each rat was placed in the chamber with the lever associated with a continuous schedule of reinforcement. For Group F-W, in these sessions, each lever press produced a single food pellet; whereas, for Group W-F in these sessions, each lever press produced 3 -s access to $5 \%$ liquid sucrose-water. The session lasted until the rats obtained 60 reinforcer deliveries. Once the rats were reliably pressing the lever, the conditions were reversed; for Group F-W and W-F, presses produced liquid sucrose-water and food-pellets, respectively. Once all rats consistently pressed the lever, the experiment began.

\section{Phase 1}

Phase 1 implemented a multiple schedule of reinforcement with two variable-interval VI components (i.e., Mult VI VI); each VI component was presented once per session. For Group F-W the session started by turning on the house light and the white noise, which signaled the beginning of the first VI component in which food pellets were delivered contingent upon lever pressing. After 30 minutes, the white noise and the house light were turned off, initiating a 1-minute blackout. After the blackout, the house light and the light above the lever were turned on, signaling the beginning of the second VI component. For the next 30 minutes, pressing the lever produced sucrosewater reinforcers. In conditions 1 to 4, the rate of sucrose water deliveries increased (i.e., VI value decreased) in the second VI component while the rate of food-pellets was held constant in the first VI component (see Table 1). 
Group W-F was exposed to the same Mult VI VI with the white noise associated with the first VI component and the light above the lever to the second VI component, except that the first VI component delivered sucrose-water and the second VI component delivered food-pellets contingent upon lever-pressing. In conditions 1 to 4 , the rate of food-pellets increased in the second VI component while the rate of sucrose-water deliveries was held constant in the first VI component (see Table 1). Conditions 5 to 8 reversed this manipulation, for Group W-F the rate of sucrose-water deliveries increased in the first VI component while the rate of food-pellets remained constant in the second VI component; whereas for Group F-W the rate of food pellets increased in the first VI component while the rate of sucrose-water deliveries remained constant in the second VI component. Table 1 shows VI values for both VI components across conditions and the number of sessions per conditions.

\section{Phase 2}

Phase 2 used a Mult VI 56 s VI 56 s schedule of reinforcement to deliver food-pellet and sucrosewater reinforcers at the same rate both in the first and the second half of the session. In condition 9, the baseline number of lever presses maintained by food-pellet and sucrose-water reinforcers was recovered for both groups (F-W and W-F) in sessions that implemented the same general procedure used in Phase 1. Then, in conditions 10 to 13 four doses of haloperidol $(0.0500,0.1000,0.1500$, and $0.2000 \mathrm{mg} / \mathrm{kg}$ selected from previous studies (Balderrama \& Aparicio, 2008), were administered intraperitoneal (IP) prior to selected experimental sessions. The drug regimen was conducted in 12-day blocks and all doses were administered 45 min before the beginning of drug sessions. On days $1,4,7$, and 10 (normal days) no injections were given. On days 2, 5, 8, and 11 (vehicle days) the rats received injections of a solution of saline water and tartaric acid $45 \mathrm{~min}$ before the beginning of the session. On days 3, 6, 9, and 12 (drug days) only one dose was injected before the beginning of the session (i.e., a different dose for each rat was assessed according to a Latin square design). Injection volume was always $1.0 \mathrm{ml} / \mathrm{kg}$. Control saline/tartaric acid injections were given to rule out any possible confounding effects of the injection procedure on the rats' behavior. Haloperidol (purchased from Sigma Chemical Co. laboratories, St. Louis, MO) was dissolved in a $0.3 \%$ solution of tartaric that which also served as vehicle solution on control days.

\section{Phase 3}

Phase 3 explored the possibility that the white noise associated with the first VI component and the light above the lever associated with the second VI component, differed from one another in controlling lever pressing in the first and the second half of the session, respectively. In conditions 14 to 17 these stimuli were reversed, the light above the lever was associated with the first VI component and the white noise was associated with the second VI component. For Group F-W the rate of sucrosewater deliveries increased in the second VI component while the rate of food-pellet deliveries was held constant in the first VI component; whereas for Group W-F the rate of food-pellet deliveries increased in the second VI component while the rate of sucrose-water deliveries was held constant in the first VI component (see Table 1).

\section{Phase 4}

In Phase 4, the Mult VI 56 s VI 56 s was reinstituted. For group F-W, food-pellets and sucrose-water reinforcers were delivered at the same rate in the first and second half of the session,; whereas for group W-F, sucrose-water and food-pellets were delivered at the same rate in the first and the second half of the session. Then, condition 19 assessed the possibility that subcutaneously administered haloperidol is more efficient in decreasing lever pressing than it is via IP. Four doses of haloperidol $(0.0125,0.0250,0.0500$, and $0.1000 \mathrm{mg} / \mathrm{kg})$ were subcutaneously (SC) administered to the rats 30 minutes before the beginning of the drug sessions 
TABLE 1

Summary of the procedure, all conditions with the number of sessions

\begin{tabular}{cccccc}
\hline \multicolumn{5}{c}{ Group } \\
\cline { 1 - 4 } & Food & Water & Water & Food \\
\multicolumn{5}{c}{ Stimulus } & \multicolumn{2}{c}{ Stimulus } \\
\cline { 2 - 5 } & Noise & Light & Noise & Light \\
\multicolumn{5}{c}{ VI schedule (s) } & \multicolumn{2}{c}{ VI schedule (s) } \\
\cline { 2 - 5 } Phase & First & Second & First & Second & Sessions \\
\hline 1 & 56 & 56 & 56 & 56 & 20 \\
2 & 56 & 28 & 56 & 28 & 20 \\
3 & 56 & 14 & 56 & 14 & 20 \\
4 & 56 & 7 & 56 & 7 & 20 \\
5 & 56 & 56 & 56 & 56 & 12 \\
6 & 28 & 56 & 28 & 56 & 12 \\
7 & 14 & 56 & 14 & 56 & 12 \\
8 & 7 & 56 & 7 & 56 & 12 \\
9 & 56 & 56 & 56 & 56 & 12 \\
\hline
\end{tabular}

Haloperidol (ip): $0.05,0.11,0.15$, and $0.20 \mathrm{mg} / \mathrm{kg}$ )

\begin{tabular}{cccccc}
\hline \multicolumn{3}{c}{ VI schedule $(\mathrm{s})$} & \multicolumn{3}{c}{ VI schedule (s) } \\
\hline Phase & First & Second & First & Second & Sessions \\
\hline 10 & 56 & 56 & 56 & 56 & 12 \\
11 & 56 & 56 & 56 & 56 & 12 \\
12 & 56 & 56 & 56 & 56 & 12 \\
13 & 56 & 56 & 56 & 56 & 12 \\
\hline \multicolumn{4}{c}{ Stimulus } & \multicolumn{3}{c}{ Stimulus } \\
\cline { 2 - 5 } & Light & Noise & Light & Noise \\
\hline \multicolumn{5}{c}{ VI schedule (s) } & \multicolumn{5}{c}{ VI schedule (s) } \\
\hline Phase & First & Second & First & Second & Sessions \\
\hline 14 & 56 & 56 & 56 & 56 & 12 \\
15 & 56 & 28 & 56 & 28 & 12 \\
16 & 56 & 14 & 56 & 14 & 12 \\
17 & 56 & 7 & 56 & 7 & 12 \\
18 & 56 & 56 & 56 & 56 & 12 \\
\hline
\end{tabular}

Haloperidol (sc): $0.0125,0.0250,0.0500$, and $0.1000 \mathrm{mg} / \mathrm{kg}$ )

\begin{tabular}{cccccc}
\hline \multicolumn{3}{c}{ VI schedule (s) } & \multicolumn{3}{c}{ VI schedule (s) } \\
\hline Phase & First & Second & First & Second & Sessions \\
\hline 19 & 56 & 56 & 56 & 56 & 12 \\
\hline
\end{tabular}

Source: (that time in our experience is enough for haloperidol to act upon the organism and maintain its maximum effectiveness for 90 minutes or more.

\section{Data analysis}

All sessions were used for the analysis. The daily records of the total number of presses and the obtained food-pellets or sucrose-water deliveries were summed up individually for each VI component. These sums were used to compute average data across sessions. For each 12-day block, a complete dose effect curve was generated for each rat, consisting of the average data from the 4 normal days and the 4 vehicle days, and the data from 1 day at each dose. Conditions 10 to 13 consisted of 4 doseeffect determinations, and condition 19 consisted of a single dose-effect determination.

\section{Results}

\section{Responding under IP pre-drug conditions, Phase 1}

The number of lever presses and obtained reinforcers per VI component under the pre-drug conditions (Phase 1) are summarized in Table 2. In conditions 1 to 4 the reinforcer rate was manipulated in the second VI component, and in conditions 5 to 8 reinforcer rate was manipulated the first VI component. With equal reinforcer rates in both components (Mult VI 56 s, VI 56 s), the number of lever presses was substantially higher in the VI component delivering food-pellets, regardless of whether that VI component was the first or the second VI component. For group F-W, the average number of presses (and obtained reinforcers) maintained by food pellets was 453.07 (27.69) and 1212.88 (24.15), respectively in conditions 1 and 5; for group W-F, the corresponding values were 407.24 (26.43) and 1276.19 (23.73), respectively. The same conditions show that for group F-W the average number of presses (and obtained reinforcers) maintained by sucrose water was 97.58 (19.19) and 227.19 (17.03), and for group W-F they were 87.31 (17.05) and 143.48 (17.60), respectively. Genera- 
lly, the number of lever presses per VI component was higher in condition 5 than in condition 1 , suggesting an effect of the rats' experience with both types of reinforcers. On average (conditions 1 and 5), however, with an equal reinforcer rate in both components, food-pellet presentation maintained approximately a number 6 -fold times higher of lever presses than did sucrose-water presentation.

For both groups, increasing the rate of sucrosewater presentation (conditions 2 to 4 for group F-W and 6 to 8 for group W-F) resulted in an increase in the average number of presses in that VI component; this was accompanied by an increase in the average number of presses in the VI component delivering food pellets, even though the rate of food-pellet presentation was unchanged, and regardless of whether the manipulation in the rate of sucrose-water was made in the first or the second half of the session. For both groups, the average number of presses increased by increasing the rate of food-pellet presentation (conditions 6 and 7 for group F-W and conditions 2 and 3 for group W-F), except at the highest rate (conditions 8 and 4 , respectively) at which the average number of presses declined. For Group W-F, the average number of presses maintained by sucrose-water increased in the first VI component with increasing rate of food-pellets in the second VI component (conditions 2 to 4), even though the rate of sucrose-water presentation was held constant in the first VI component. In contrast, for Group F-W the average number of presses maintained by sucrose-water presentation decreased in the second VI component with increasing rate of food-pellets in the first VI component (see Table 2).

\section{Effects of IP haloperidol, Phase 2}

For both groups, the data of condition 9 (the return to VI 56 s, VI 56 s) were similar (not shown in Table 2) to those obtained in condition 5. For group F-W average number of presses (and obtained reinforcers) maintained by food-pellet presentation and sucrose-water presentation was 1576.25 (24.5) and 176.75 (23.7), respectively,; whereas for group W-F, the average number of presses (and obtained rein- forcers) maintained by sucrose-water presentation and food-pellet presentation was 767.25 (23.0) and 1636.5 (29.2), respectively. Once again, the number of lever presses was substantially higher in the VI component delivering food pellets.

Haloperidol dose-effect functions on lever pressing (conditions 10 to 13) for Groups F-W and W-F are shown in Figures 1 and 2, respectively. The corresponding functions for the reinforcers obtained are shown in Figures 3 and 4. In each figure, columns 1-4 show data from successive dose-effect determinations (conditions 10 to 13) via IP injection. Several features are evident in these functions Uunder no-drug and vehicle conditions (unconnected symbols), the number of lever presses maintained by pellet presentation was uniformly higher than the number of lever presses maintained by sucrose-water presentation (replicating the data from conditions 1, 5, and 9). Generally, haloperidol produced dose-related decreases in lever pressing and obtained reinforcers in both components. For most of the rats, the first dose-effect determination yielded roughly parallel functions in both components. Although there were a few exceptions (e.g., R53), these decreases in lever pressing (figures 1 and 2) were not accompanied by substantial reductions in the rate of reinforcer delivery in either VI component. That is, most of the rats continued to receive reinforcers in both components figures 3 and 4).

Visual inspection from left to right of columns 1-4 reveals that the effects of haloperidol on lever pressing increased across successive dose-effect determinations. That is, sensitization to the response-suppressing effects of haloperidol developed. This was typically accompanied by a decline in the rate of reinforcer presentation. Interestingly, for most of the rats, sensitization appeared to develop more quickly (R50, R51, R52, R53, R54, R57), and to a greater extent (R52, R53, R54, R57), in the VI component delivering sucrose-water than in the VI component delivering food-pellets. Thus, over the last two or three determinations of the dose-effect function, pressing the lever maintained sucrose-water presentations was more likely to be suppressed at a given dose of haloperidol. 
TABLE 2

Pre-drug IP presses and obtained food-pellets or sucrose-water deliveries in Phase 1

\begin{tabular}{|c|c|c|c|c|c|c|c|c|c|c|c|c|}
\hline $\mathrm{C}$ & VI s & $\mathrm{F} \& W$ & Presses & Pellets & Presses & Water & $\mathrm{C}$ & VI s & Presses & Pellets & Presses & Water \\
\hline \multirow[t]{5}{*}{1} & $56-56$ & R-50 & 707.95 & 28.30 & 158.15 & 23.85 & 5 & $56-56$ & 2083.92 & 27.50 & 510.08 & 25.67 \\
\hline & & R-51 & 316.65 & 27.55 & 67.40 & 12.50 & & & 413.33 & 22.75 & 42.25 & 7.58 \\
\hline & & R-52 & 319.60 & 26.50 & 92.70 & 21.05 & & & 1166.50 & 22.83 & 147.83 & 14.67 \\
\hline & & R-53 & 468.07 & 28.40 & 72.05 & 19.35 & & & 1187.75 & 23.50 & 208.58 & 20.17 \\
\hline & & Mean & 453.07 & 27.69 & 97.58 & 19.19 & & & 1212.88 & 24.15 & 227.19 & 17.02 \\
\hline \multirow[t]{5}{*}{2} & $56-27$ & R-50 & 755.95 & 30.05 & 275.60 & 47.40 & 6 & $27-56$ & 2589.17 & 59.42 & 297.83 & 25.08 \\
\hline & & $\mathrm{R}-51$ & 298.95 & 28.85 & 99.87 & 33.20 & & & 707.42 & 57.17 & 165.50 & 23.17 \\
\hline & & R-52 & 173.58 & 20.68 & 128.35 & 39.75 & & & 1188.58 & 58.42 & 110.67 & 21.00 \\
\hline & & R-53 & 408.00 & 23.60 & 108.45 & 36.30 & & & 2242.42 & 60.58 & 172.58 & 22.67 \\
\hline & & Mean & 409.12 & 25.80 & 153.07 & 39.16 & & & 1681.90 & 58.90 & 186.65 & 22.98 \\
\hline \multirow[t]{5}{*}{3} & $56-14$ & R-50 & 1264.35 & 30.15 & 612.05 & 92.75 & 7 & $14-56$ & 1571.92 & 117.17 & 189.75 & 21.83 \\
\hline & & R-51 & 435.75 & 29.50 & 101.20 & 42.65 & & & 649.25 & 118.17 & 125.00 & 22.42 \\
\hline & & $\mathrm{R}-52$ & 655.10 & 28.10 & 295.25 & 77.20 & & & 1160.92 & 106.58 & 72.92 & 17.75 \\
\hline & & R-53 & 748.75 & 29.80 & 189.30 & 70.50 & & & 1517.75 & 120.08 & 151.50 & 21.92 \\
\hline & & Mean & 775.99 & 29.39 & 299.45 & 70.78 & & & 1224.96 & 115.50 & 134.79 & 20.98 \\
\hline \multirow[t]{5}{*}{4} & $56-7$ & R-50 & 2026.65 & 27.85 & 1168.55 & 176.90 & 8 & $7-56$ & 378.33 & 195.25 & 103.58 & 19.92 \\
\hline & & R-51 & 311.65 & 25.45 & 20.60 & 13.45 & & & 333.67 & 209.25 & 82.92 & 21.58 \\
\hline & & $\mathrm{R}-52$ & 1191.45 & 26.00 & 454.40 & 115.25 & & & 385.17 & 203.42 & 32.50 & 14.08 \\
\hline & & $\mathrm{R}-53$ & 968.70 & 27.15 & 357.30 & 132.20 & & & 392.00 & 201.25 & 83.67 & 20.00 \\
\hline & & Mean & 1124.61 & 26.61 & 500.21 & 109.45 & & & 372.29 & 202.29 & 75.67 & 18.90 \\
\hline $\mathrm{C}$ & VI s & W\&F & Presses & Water & Presses & Pellets & $\mathrm{C}$ & VI s & Presses & Water & Presses & Pellets \\
\hline \multirow[t]{5}{*}{1} & $56-56$ & R-57 & 55.00 & 17.10 & 142.00 & 22.80 & 5 & $56-56$ & 79.75 & 19.83 & 399.58 & 23.50 \\
\hline & & R-55 & 59.75 & 16.55 & 260.60 & 24.10 & & & 132.17 & 12.00 & 1639.42 & 22.58 \\
\hline & & R-56 & 179.50 & 20.35 & 764.80 & 30.00 & & & 307.00 & 23.00 & 1917.92 & 20.58 \\
\hline & & R-54 & 55.00 & 14.20 & 461.55 & 28.80 & & & 55.00 & 15.58 & 1147.83 & 28.25 \\
\hline & & Mean & 87.31 & 17.05 & 407.24 & 26.43 & & & 143.48 & 17.60 & 1276.19 & 23.73 \\
\hline \multirow[t]{5}{*}{2} & $56-27$ & R-57 & 83.85 & 19.85 & 193.45 & 50.80 & 6 & $27-56$ & 291.25 & 37.83 & 420.25 & 23.58 \\
\hline & & $\mathrm{R}-55$ & 166.75 & 21.60 & 1120.40 & 60.20 & & & 435.17 & 39.58 & 1511.25 & 29.33 \\
\hline & & R-56 & 167.45 & 22.60 & 714.40 & 42.30 & & & 381.17 & 44.08 & 2396.33 & 28.83 \\
\hline & & R-54 & 112.50 & 22.70 & 491.90 & 54.55 & & & 123.67 & 33.17 & 1237.58 & 27.17 \\
\hline & & Mean & 132.64 & 21.69 & 630.04 & 51.96 & & & 307.81 & 38.67 & 1391.35 & 27.23 \\
\hline \multirow[t]{5}{*}{3} & $56-14$ & R-57 & 79.95 & 19.90 & 233.95 & 102.65 & 7 & $14-56$ & 358.00 & 75.58 & 640.92 & 27.17 \\
\hline & & R-55 & 173.55 & 14.05 & 1179.10 & 114.95 & & & 902.17 & 84.50 & 1783.50 & 30.67 \\
\hline & & R-56 & 314.50 & 19.15 & 1907.50 & 128.20 & & & 608.42 & 87.42 & 2900.17 & 29.83 \\
\hline & & $\mathrm{R}-54$ & 119.15 & 19.95 & 919.00 & 118.25 & & & 253.17 & 70.25 & 1093.17 & 28.50 \\
\hline & & Mean & 171.79 & 18.26 & 1059.89 & 116.01 & & & 530.44 & 79.44 & 1604.44 & 29.04 \\
\hline \multirow[t]{5}{*}{4} & $56-7$ & R-57 & 63.50 & 16.45 & 284.85 & 188.65 & 8 & $7-56$ & 582.83 & 150.25 & 574.58 & 27.75 \\
\hline & & $\mathrm{R}-55$ & 133.90 & 8.30 & 247.75 & 158.35 & & & 791.75 & 139.92 & 2046.42 & 29.58 \\
\hline & & $\mathrm{R}-56$ & 312.95 & 21.45 & 573.25 & 232.15 & & & 668.17 & 156.67 & 2781.25 & 28.58 \\
\hline & & R-54 & 117.65 & 17.05 & 320.75 & 185.65 & & & 669.92 & 147.58 & 984.42 & 26.33 \\
\hline & & Mean & 157.00 & 15.81 & 356.65 & 191.20 & & & 678.17 & 148.60 & 1596.67 & 28.06 \\
\hline
\end{tabular}

Source: own work 
FIGURE 1

For Group F-W, log (base 10) of lever presses as a function of drug conditions. From left to right the multiple panels are organized according to determinations of drug conditions, and from top to bottom according to individuals


$\bigcirc \bigcirc$

$\bigcirc 0$
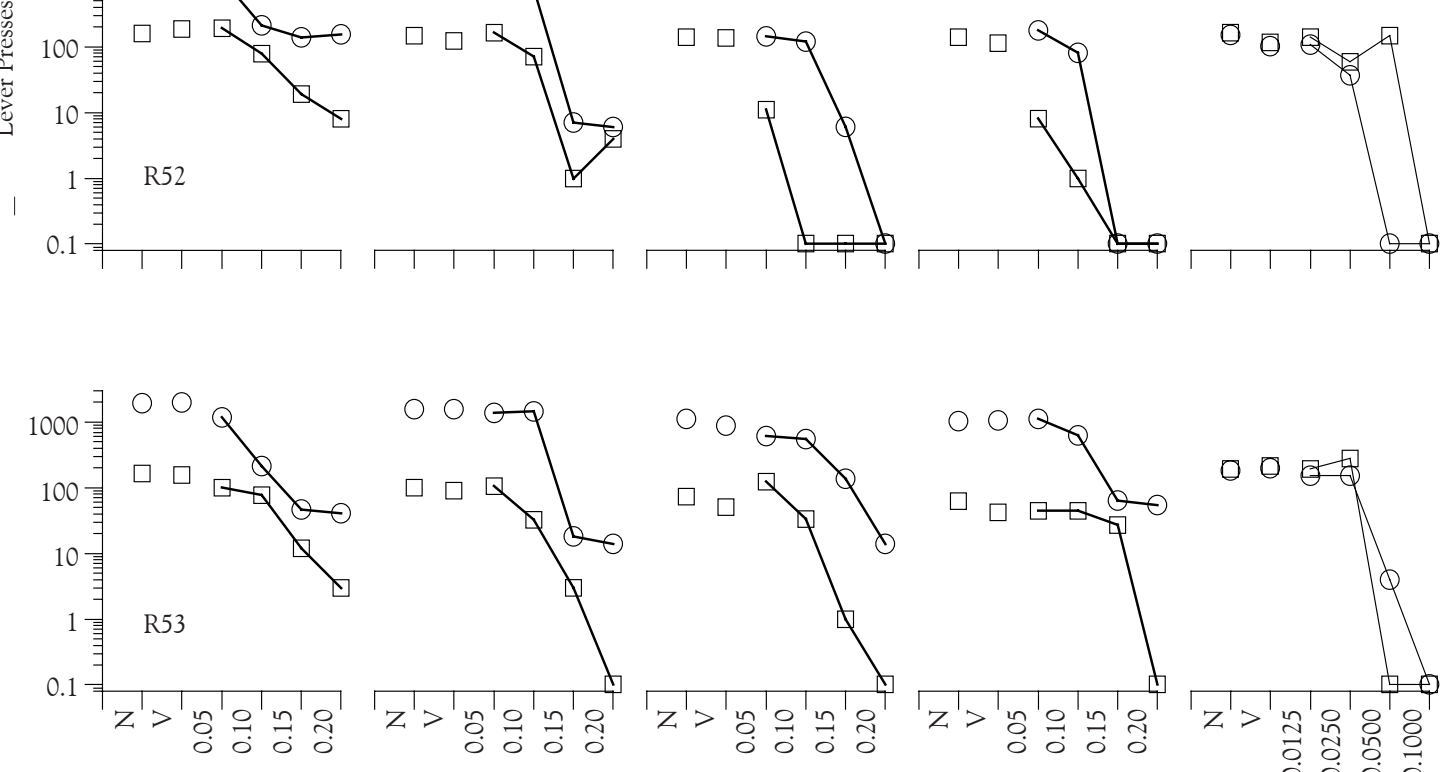

$00 \bigcirc 8$

$\oslash$ Food Pellets

$\square$ Sucrose Water

Drug Conditions

Source: own work 
FIGURE 2

For Group W-F, log (base 10) of lever presses as a function of drug conditions. Other details as in Fig. 1
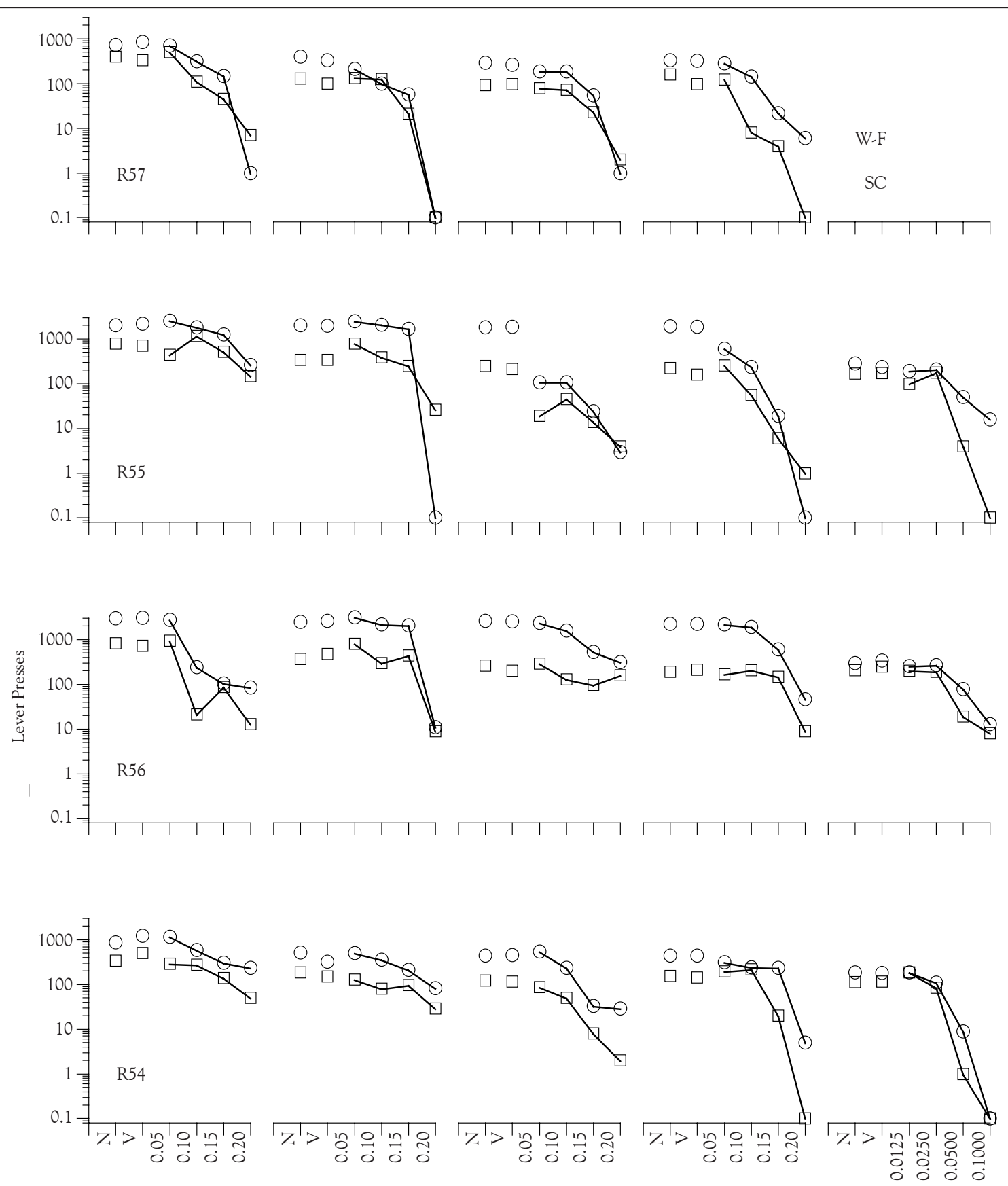

- Food Pellets $\quad \square$ Sucrose Water

Drug Conditions

Source: own work 
FIGURE 3

For Group F-W, log (base 10) of produced pellets or sucrose water as a function of drug conditions. Other details as in Fig. 1

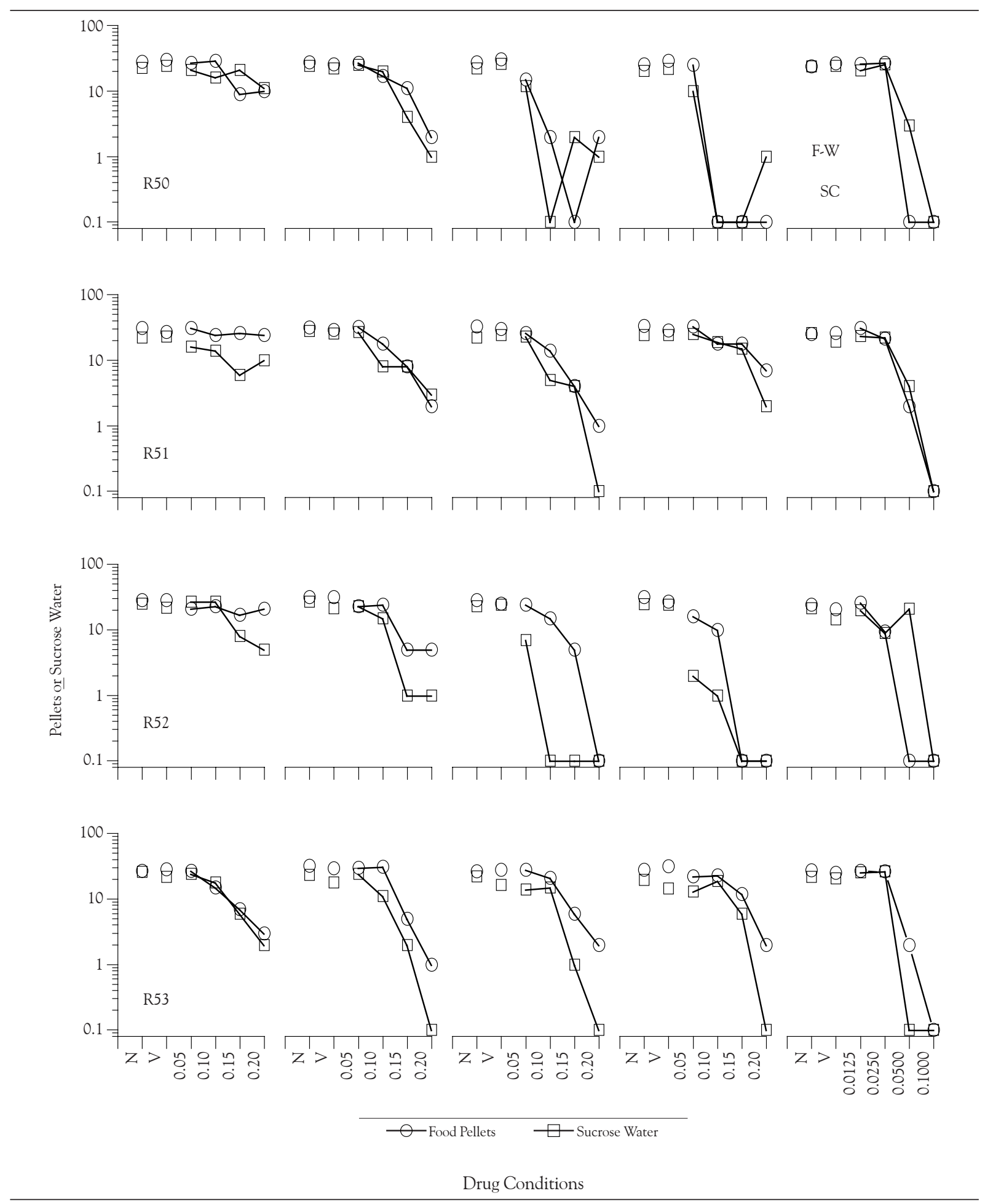

Source: own work 
FIGURE 4

For Group W-F, log (base 10) of produced pellets or sucrose water as a function of drug conditions. Other details as in Fig. 1

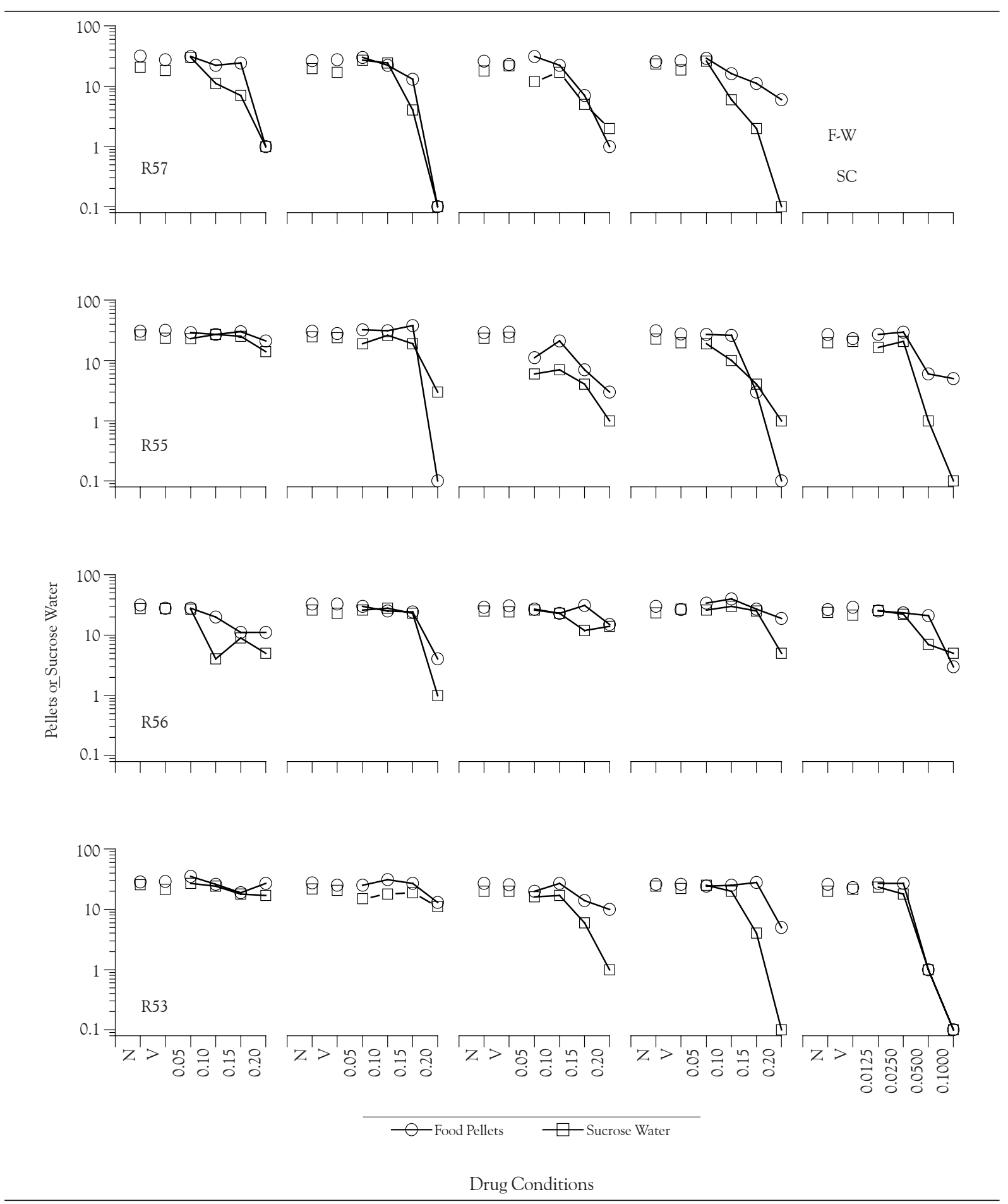

Source: own work 


\section{Responding under SC pre-drug conditions, Phase 3}

Table 3 summarizes the data for lever presses and obtained reinforcers for conditions (14 to 17) where the light above the lever was associated with the first VI component, and the white noise was associated with the second VI component. The rate of the reinforcers was manipulated in the second VI component, providing sucrose-water for group F-W and food-pellets for group W-F. With equal rate of reinforcers in both components (condition 14), the number of lever presses was higher in the VI component delivering food pellets than in the component delivering sucrose water, regardless of whether that VI component was programmed in the first or the second half of the session. Table 3 shows for group F-W, the average number of lever presses (and obtained reinforcers) maintained by food-pellet presentation and sucrose-water presentation was 98.58 (21.17) and 64.98 (15.33), respectively; whereas for group W-F, these values were 138.64 (25.28) and 82.81 (19.44), respectively. For Group F-W, the average number of presses maintained by food-pellets increased in the first VI component with increasing rate of sucrose-water in the second VI component (conditions 15 to 17), even though the rate of food-pellet presentation was held constant in the first VI component. In contrast, for group W-F the average number of presses maintained by sucrose-water decreased in the first VI component with increasing rate of food-pellets in the second VI component (but see rat 56). Increasing the rate of sucrose-water presentation in the second VI component (i.e. group F-W) produced a concomitant increase in of lever pressing in that component. However, group W-F shows unsystematic changes in lever pressing with increasing rate of food-pellet presentation in the second VI component.

\section{Effects of SC haloperidol, Phase 4}

For group W-F, the data in condition 18 (the return to VI 56 s, VI 56 s) were consistent with those obtained in condition 9, the average values of presses (and average obtained reinforcers) maintained by sucrose-water and food-pellets were 137 (18) and 345 (27), respectively (data not shown in Table 3). However, for group F-W, the average number of lever presses (and obtained reinforcers) maintained by food-pellet presentation was lower than the average number presses maintained by sucrose-water presentation: 178 (28) versus 229 (20).

Column 5 of Figures 1- 4 shows dose-effect functions on lever pressing and obtained reinforcers for a single determination of haloperidol via SC administration (condition 19). Haloperidol produced dose-related decreases in lever pressing and obtained reinforcers in both VI components. However, there are two notable differences in these data compared to those obtained during the IP Phase 2. First, the number of lever presses per component was similar for the two types of reinforcers. Second, haloperidol was more potent in decreasing responses to the lever via $\mathrm{SC}$ administration than via IP administration (note the lower dose range for SC administration). For R53, R54, and R55, responding maintained by sugar water was more sensitive to SC administration of haloperidol; whereas, for $\mathrm{R} 50$ and $\mathrm{R} 52$, responding maintained by food pellets was more sensitive to SC administration of haloperidol. For R51 and R56 responding in both VI components was about equally sensitive tc.SC administration of haloperidol.

\section{Discussion}

Determining the relative hedonic value of food-pellet and sucrose-water reinforcers: Responding under pre-drug conditions, Phase 1

In the present study, we used multiple schedules of reinforcement with two VI components, one VI component delivered food-pellets and the other VI component delivered sucrose-water reinforcers. With equal rate of reinforcers in both components (Mult VI 56 s, VI 56 s), we found a substantially higher number of lever presses in the VI component delivering food-pellets than in the VI component delivering sucrose water; this occurred regardless of whether that VI component was 
TABLE 3

Pre-drug SC presses and obtained food-pellets or sucrose-water deliveries in Phase 3

\begin{tabular}{|c|c|c|c|c|c|c|c|c|c|c|c|}
\hline $\mathrm{C}$ & VI s & $\mathrm{F} \& W$ & Presses & Pellets & Presses & Water & $W \& F$ & Presses & Water & Presses & Pellets \\
\hline \multirow[t]{5}{*}{14} & $56-56$ & R-50 & 138.25 & 21.58 & 108.92 & 16.33 & R-55 & 68.42 & 18.58 & 115.42 & 22.83 \\
\hline & & R-51 & 99.25 & 22.75 & 74.83 & 18.58 & R-56 & 107.17 & 21.25 & 203.25 & 32.50 \\
\hline & & $\mathrm{R}-52$ & 104.58 & 22.42 & 54.83 & 17.50 & R-54 & 72.83 & 18.50 & 97.25 & 20.50 \\
\hline & & R-53 & 52.25 & 17.92 & 21.33 & 8.92 & & & & & \\
\hline & & Mean & 98.58 & 21.17 & 64.98 & 15.33 & & 82.81 & 19.44 & 138.64 & 25.28 \\
\hline \multirow[t]{5}{*}{15} & $56-27$ & R-50 & 168.75 & 23.17 & 128.17 & 34.83 & R-55 & 30.67 & 12.42 & 185.08 & 46.50 \\
\hline & & R-51 & 146.75 & 25.92 & 110.75 & 39.50 & R-56 & 152.17 & 23.33 & 337.58 & 53.08 \\
\hline & & $\mathrm{R}-52$ & 117.08 & 22.08 & 75.33 & 31.67 & R-54 & 45.08 & 16.92 & 96.75 & 39.17 \\
\hline & & R-53 & 88.25 & 21.75 & 38.58 & 22.92 & & & & & \\
\hline & & Mean & 130.21 & 23.23 & 88.21 & 32.23 & & 75.97 & 17.56 & 206.47 & 46.25 \\
\hline \multirow[t]{5}{*}{16} & $56-14$ & R-50 & 183.17 & 25.33 & 332.42 & 74.25 & R-55 & 13.75 & 6.42 & 158.83 & 74.75 \\
\hline & & R-51 & 165.00 & 24.83 & 135.08 & 66.08 & R-56 & 139.92 & 22.50 & 268.08 & 96.17 \\
\hline & & R-52 & 135.17 & 24.33 & 97.67 & 48.92 & R-54 & 54.08 & 17.42 & 95.83 & 53.42 \\
\hline & & $\mathrm{R}-53$ & 117.42 & 23.67 & 61.42 & 40.17 & & & & & \\
\hline & & Mean & 150.19 & 24.54 & 156.65 & 57.35 & & 69.25 & 15.44 & 174.25 & 74.78 \\
\hline \multirow[t]{5}{*}{17} & $56-7$ & $\mathrm{R}-50$ & 233.50 & 23.33 & 649.25 & 145.08 & R-55 & 23.58 & 7.58 & 104.58 & 85.92 \\
\hline & & R-51 & 202.67 & 25.17 & 158.83 & 101.42 & R-56 & 143.17 & 35.92 & 289.83 & 180.58 \\
\hline & & $\mathrm{R}-52$ & 141.42 & 26.42 & 151.25 & 91.75 & R-54 & 51.58 & 15.50 & 121.67 & 101.50 \\
\hline & & R-53 & 172.67 & 32.67 & 122.67 & 64.67 & & & & & \\
\hline & & Mean & 187.56 & 26.90 & 270.50 & 100.73 & & 72.78 & 19.67 & 172.03 & 122.67 \\
\hline
\end{tabular}

Source: own work

programmed in the first half of the session (group F-W) or in the second half of the session (group W-F). Pressing the lever, however, was higher in the redetermination than in the original determination, suggesting that performance was enhanced with the rats' experience with both types of reinforcers. These findings are in keeping with the notion that the reinforcing (i.e., hedonic) value of a 45 $\mathrm{mg}$ food pellet is higher than that of a $0.05 \mathrm{cc}$ drop of $5 \%$ sucrose water (e.g., Weatherly \& Moulton, 2001; Weatherly et al., 1999).

Generally, lever pressing increased with increasing the reinforcer rate, this result occurred regardless of whether the manipulation in the rate of reinforcers was made in the first or in the second VI component. At the highest rate of food-pellet reinforcers (VI 7 s), however, the number of lever presses decreased in that component, probably due to satiation, given the large quantity (about 200) of food-pellets obtained in that VI component.

For Group W-F, increasing the rate of foodpellet presentation in the second VI component produced a concomitant increase in lever pressing maintained by sucrose-water presentation, even though the rate of sucrose-water presentation was held constant in the first VI component. These data resembled those documented in several studies (e.g., Weatherly et al., 1999; Weatherly, Davis et al., 2000; Weatherly \& Moulton, 2001; Weatherly, Rue et al., 2000), and may qualify as induction because receiving food pellets in the second VI schedule, rather than sucrose water, might represent an improvement in the upcoming conditions of reinforcement (Weatherly et al., 2001, 2002). 
Interestingly, however, we found the same result for Group F-W; lever pressing maintained by food pellets increased in the first VI component by increasing the rate of sucrose-water presentation in the second VI component. This result may also qualify as induction, given that the number of lever presses increased in both VI components. Thus, regardless of the relative hedonic value of reinforcers presented in the first or the second VI component, increasing the reinforcer rate in the second VI component produced an increase in responding in the first (unchanged) VI component.

Another finding was that the number of lever presses maintained by sucrose-water presentation decreased in the second (unchanged) VI component as a function of increasing the rate of food-pellet presentation in the first VI component (Group F-W). This result can be considered an example of behavioral contrast, in which the response rate in an unchanged component of a multiple schedule decreases as a function of an increase in the reinforcer rate in another component (Bouzas \& Baum, 1976). Interestingly, the number of lever presses maintained by food-pellet presentation actually increased in the second (unchanged) VI component as a function of increasing the rate of sucrose-water presentation in the first VI component (Group W-F), for which we have no explanation.

\section{Assessing IP administration of haloperidol,} Phase 2

Consistent with the results of Phase 1 , the redetermination of the Mult VI 56 s VI 56 s schedule during the no-drug and vehicle conditions of Phase 2 showed that the number of lever presses maintained by food-pellet presentation was uniformly higher than the number of lever presses maintained by sucrose-water presentation, confirming our conclusion that the reinforcing value of a $45 \mathrm{mg}$ food pellet was greater than that of 0.05 cc of a $5 \%$ sucrose solution.

In both components, the IP administration of haloperidol produced dose-related decreases in the number of lever presses. In several cases, these decreases were not accompanied by substantial re- ductions in the rate of reinforcer delivery in either VI component. Even at the highest dose of haloperidol $(0.20 \mathrm{mg} / \mathrm{kg})$, several of the rats continued to produce reinforcers in both VI components. These results are consistent with the view that decreases in food-maintained operant responding and decreases in feeding produced by neuroleptics are not necessarily the result of decreased reinforcing strength (Salamone et al, 1997) or decreased appetite (Salamone et al, 2002).

The suppressive effects of haloperidol on lever pressing increased across successive dose-effect determinations; that is, the sensitization to the response-suppressive effects of haloperidol developed in both components. Inspection of the data in Figures 1 and 2 indicates that sensitization appeared to develop more rapidly (i.e., after fewer administrations), and to a greater extent, in the VI component delivering sucrose-water than in the component delivering food pellets, suggesting ratesuppressive effects of haloperidol that depended on the type of reinforcer. To further assess the possibility that the type of reinforcer altered the resistance of pressing the lever under the suppressive effects of haloperidol, we used a statistic proposed by Nevin, Smith and Roberts(1987) to represent the overall effects of the behaviorally disruptive event (in this case, the administration of haloperidol) on lever pressing maintained by food-pellets and sucrose-water reinforcers. We used the following equation in order to compute the proportion of baseline responding:

$$
\bar{p}=\frac{\sum x_{i} p_{i}}{\sum x_{i}}
$$

Where $\mathrm{x}_{\mathrm{i}}$ is the ith drug dose and $\mathrm{p}_{\mathrm{i}}$ the proportion of baseline responding produced by that dose. Thus, Equation 1 quantifies the overall effects of a range of values (doses) of a "disruptive" variable (haloperidol in this case) on responding. Note that, because the suppressive effects of haloperidol are dose-related, Equation 1 gives greatet importance to higher doses. Accordingly, $\bar{p}$ is a weighted mean of the proportional reductions in lever pressing produced by haloperidol. 
The overall means are displayed to the far right of Figure 5, it shows the $\bar{p}$ value as a function of the successive i.p. dose-effect curve determination) for Group F-W (top graph) and Group W-F (bottom graph). Two results are evident: 1) $\bar{p}$ is higher for Group W-F (range from 0.25 to 0.55 ) than for Group F-W (range from 0.10 to 0.22 ), indicating that pressing the lever was more resistant to the suppressive effects of haloperidol in Group W-F than in Group F-W; and 2) $\bar{p}$ is higher for sucrose-water than for food-pellets reinforcers, indicating that lever pressing maintained by 0.05 cc of $5 \%$ sucrose-water presentation was more resistant to the suppressive effects of haloperidol than was the lever pressing maintained by $45 \mathrm{mg}$ food-pellet presentation.

Interestingly, the cumulative proportional ratesuppressive effects of haloperidol, summarized using the $\bar{p}$ statistic, were greater for group F-W than for Group W-F, also, the cumulative proportional ratesuppressive effects of haloperidol were greater for lever presses maintained by food-pellet reinforcers than for lever presses maintained by sucrose-water reinforcers. These findings are difficult to conciliate with the anhedonia hypothesis which might predict: 1) a similar $\bar{p}$ value for groups $\mathrm{F}-\mathrm{W}$ and W-F, because the suppressive lever-pressing effect of haloperidor should be the same regardless of the order in which the food-pellets and sucrose-water reinforcers were produced in the session, and 2) a higher $\bar{p}$ value for food-pellets than for sucrosewater reinforcers, because pressing the lever maintained by reinforcers of high hedonic value (foodpellets) should be more resistant to suppression by haloperidol than pressing the lever maintained by reinforcers of low hedonic value (sucrose-water).

\section{Reversing the stimulus associated with the first and the second VI component, Phase 3}

Phase 3 explored the possibility that in phases 1 and 2 the white noise and the light above the lever may differed from one another in controlling lever presses in the first and the second half of the session, respectively. Thus, it reversed the order in which these stimuli were presented in the session; the light above the lever was associated with the first VI component, and the white noise was associated with the second VI component.

With the rats responding to the Mult VI $56 \mathrm{~s}$ VI $56 \mathrm{~s}$, again pressing the lever was highest in the VI component providing food pellets; this occurred regardless of whether that VI component was the first or the second VI component programmed in the session. This result is consistent with findings of conditions 1, 5, and 9 (and with those of normal and vehicle days in conditions 10-13 of phase 2 ) and further support the notion that the hedonic value of food-pellet reinforcers is higher than that of sucrose-water reinforcers, Weatherly \& Moulton, 2001; Weatherly et al., 1999).

The possibility that the white noise and the light above the lever had different effectiveness in controlling lever presses, was discarded by the results of conditions 15 to 17 ; increasing the rate of reinforcers in the second VI component produced results in the first VI component that were consistent with findings corresponding to conditions 2 to 4 and 6 to 8. For Group F-W pressing the lever maintained by food-pellet reinforcers increased in the first VI component by increasing rate of sucrose-water reinforcers in the second VI component, whereas for Group W-F pressing the lever maintained by sucrose-water presentations decreased with increasing rate of food-pellets in the second VI component. The unsystematic changes in the average number of lever presset displayed by Group W-F in the second VI component, and the fact that the overall performance of both groups was considerably lower in Phase 3 (less responding occurred in both VI components) than the overall performance in phases 1 and 2, strongly suggest that the administration of haloperidol in conditions 10 to 13 of Phase 2 produced cumulative effects that were carried over to Phase 3. Thus, a reasonable interpretation of these data is that haloperidol acted upon the motor system to slow down the lever-pressing behavior (Aparicio, 2003a, 2007b; Cheeta et al., 1995; Fiberger et al., 1976; Nowen, Arrizi, Carlson \& Salamone, 2001; Pitts \& Horvitz, 2000; Salamone, 1992; Tombaugh et al., 1979). 


\section{FIGURE 5}

For F-W (top panel) and W-F (bottom), $\bar{p}$ values for each i.p. dose-effect determination (1-4), along with overall mean values (far right). Data for lever pressing maintained by food pellets and sucrose water are presented in black bars and grey bars, respectively. Vertical lines show S.E

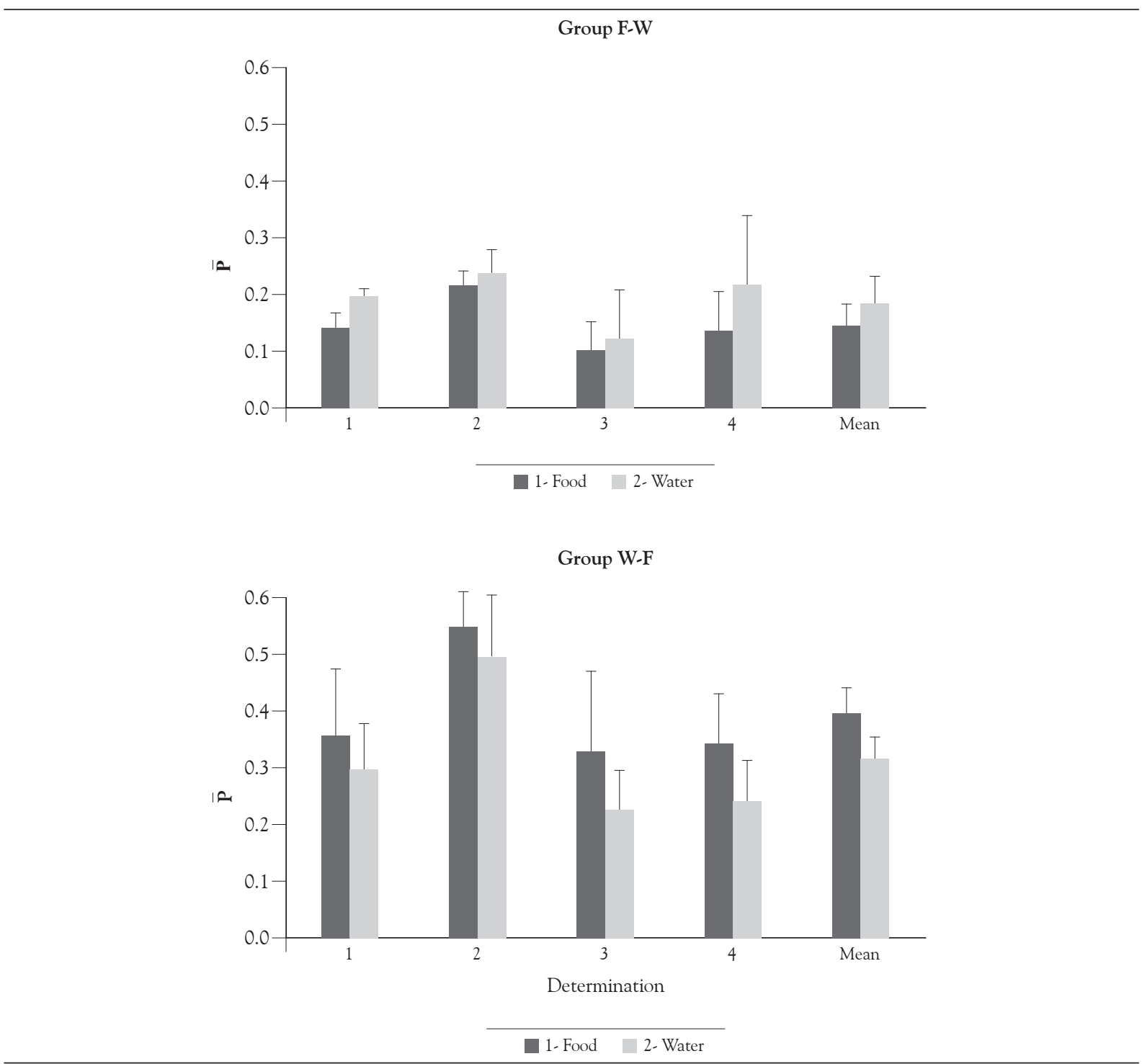

Source: own work

\section{Effects of SC haloperidol, Phase 4}

In the last redetermination (condition 18) to the Mult VI 56 s VI 56 s, only one the W-F group of rats showed results consistent with previous redeterminations and the original determination to the Mult VI 56 s VI 56 s; that is, food-pellet presentations maintained more lever presses (Mean of 345) than did sucrose-water presentations (Mean of 137). For Group F-W, pressing the lever maintained by food-pellets was slightly lower (Mean of 178 presses) than responding maintained by sucrose-water reinforcers (Mean of 229 presses). This result cannot be interpreted as a reduction in the hedonic value of food-pellets due to the rats' experience with haloperidol in Phase 2, because Group F-W 
produced and consumed more food-pellet (Mean of 28) than sucrose-water reinforcers (Mean of 20) in condition 18; moreover, for both groups of rats, F-W and W-F, the number of food-pellets and sucrose-water reinforcers obtained in condition 18 was similar to that obtained in the previous phases. Thus, a more viable explanation for the results of condition 18 is that the administration of haloperidol in Phase 2 produced cumulative suppressive effects on pressing the lever which resulted in a reduction of the overall performance of the rats, and these effects were carried over to phases 3 and 4 .

Consistent with the results of Phase 2, haloperidol produced dose-related decreases in lever pressing and obtained reinforcers in both VI components. Although haloperidol was more potent in decreasing lever pressing through s.c. administration than through i.p. administration, the dose-effect functions for both reinforcers were similar during s.c. administration, suggesting that lever pressing maintained by food-pellets and lever pressing maintained by sucrose-water reinforcers were equally resistant to the disruptive effects of haloperidol. To further assess this possibility, we again used Nevin et al. (1987) statistic to represent the overall effects of the behavioral disruptive variable, haloperidol, on lever pressing maintained by food-pellets and sucrose-water reinforcers.

Figure 6 shows the $\bar{p}$ value computed for lever presses maintained by food-pellets and sucrosewater reinforcers. For Group F-W (top graph) $\bar{p}$ was again higher for sucrose-water than for foodpellet reinforcers, indicating that the pressing of the lever maintained by sucrose-water reinforcers was more resistant to the suppressive effects of haloperidol than the pressing of the lever maintained by food-pellet reinforcers. Group W-F (bottom graph) shows similar values for $\bar{p}$ for sucrosewater and food-pellets reinforcers, indicating that the pressing of the lever maintained by food-pellet reinforcers was similarly resistant to the suppressive effects of haloperidol to the pressing of the lever maintained by sucrose-water reinforcers. Thus, only for Group F-W the cumulative proportional rate-suppressive effects of haloperidol, summarized using the $\bar{p}$ statistic, were greater for lever presses maintained by food-pellets than for lever presses maintained by sucrose-water reinforcers. Again, this finding does not appear to be consistent with the anhedonia hypothesis; why should pressing the lever maintained by a reinforcer with high hedonic value be less resistant to the disruptive effects of haloperidol?

\section{Conclusions}

\section{FIGURE 6}

For F-W (top panel) and W-F (bottom), $\bar{p}$ values for the s.c. dose-effect determination. Other details are as in Fig. 5
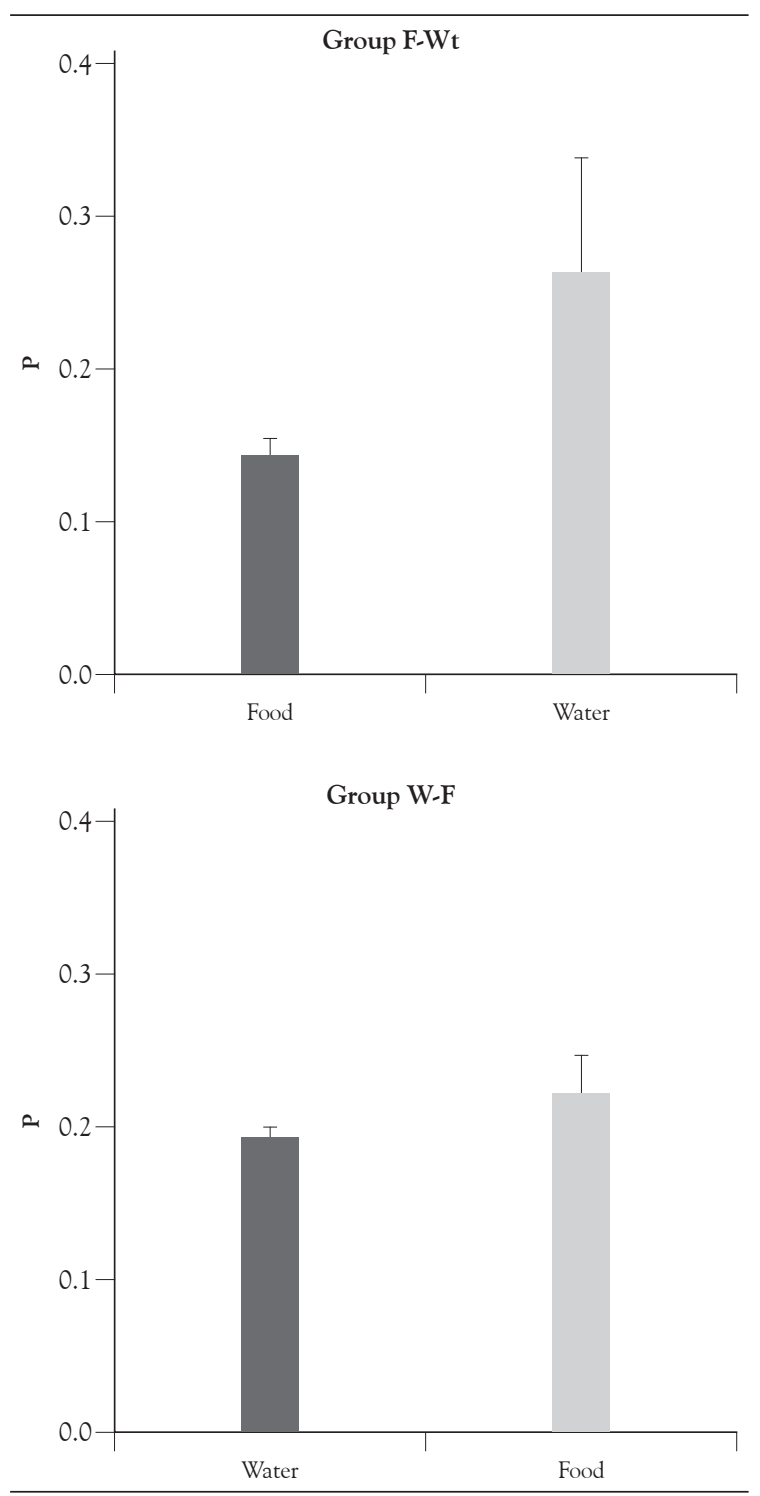

Source: own work 
In summary, under VI schedules, presentation of $45 \mathrm{mg}$ food pellets maintained more responding than did $0.05 \mathrm{cc}$ of $5 \%$ sucrose, suggesting that the pellets were more effective reinforcers. However, responding maintained by the sucrose solution was slightly more resistant to disruption by haloperidol (at least as quantified by $\bar{p}$ ). In our view, an interpretation based upon "anhedonia" produced by dopamine blockade would be an oversimplification and would be potentially misleading.

\section{References}

Aparicio, C. F. (1998). Assessing haloperidol in rats with the barrier choice paradigm. Suma Psicológica, 5, 1-20.

Aparicio, C. F. (1999). The barrier choice paradigm: Haloperidol reduces sensitivity to reinforcement. Behavioural Processes, 48, 57-67.

Aparicio, C. F. (2003a). Haloperidol affects choice and changes in preference: The barrier choice paradigm. Mexican Journal of Behavior Analysis, 29, 31-61.

Aparicio, C. F. (2003b). Effects of haloperidol in a variable reinforcement environment. Mexican Journal of Behavior Analysis, 29, 119-232.

Aparicio, C. F. (2007a). Haloperidol, dynamics of choice, and the parameters of the matching law. Behavioural Processes, 75, 206-212.

Aparicio, C. F. (2007b). Dopamine and operant behavior. In J. Juarez (Ed.), Neurobiology of Hedonism (pp. 111-138). México: El Manual Moderno.

Aparicio, C. F. \& Velasco, F. (2003). The barrier choice paradigm: Assessing haloperidol with eight response alternatives and two travel requirements. Universitas Psychologica, 2, 109-135.

Balderrama, J. A. \& Aparicio, C. F. (2008). Effects of dopamine agonists and antagonists in variable reinforcing environments. Universitas Psychologica, 7 (2), 507-533.

Blundell, J. E. (1987). Structure, process, and mechanisms: Case studies in psychopharmacology of feeding. In L. L. Iversen, S. D. Iversen \& S. H. Snyder, (Eds.), Handbook of psychopharmacology (pp. 123-182). New York: Plenum Press.
Bouzas, A. \& Baum, W. M. (1976). Behavioral contrast of time allocation. Journal of the Experimental Analysis of Behavior, 25, 179-184.

Cheeta, S., Brooks, S. \& Willner, P. (1995). Effects of reinforcer sweetness and the D2/D3 antagonist raclopride on progressive ratio performance. Behavioural Pharmacology, 6, 127-132.

Clifton, P. G., Rusk, I. N. \& Cooper, S. J. (1991). Effects of dopamine D1 and dopamine D2 antagonists on free feeding and drinking patterns of rats. Behavioural Neuroscience, 105, 272-281.

Cousins, M. S., Atherton, A., Turner L. \& Salamone, J. D. (1996). Nucleus accumbens dopamine depletions alter relative response allocation in a T-maze cost/benefit task. Behavior Brain Research, 74, 189-197.

Cousins, M. S., Sokolowski, J. D. \& Salamone, J. D. (1994). Different effects of nucleus accumbens and ventrolateral striatal dopamine depletions on instrumental response selection in the rat. Pharmacology, Biochemistry, and Behavior, 46, 943-951.

Cousins, M. S., Wei, W. \& Salomone, J. D. (1994). Pharmacological characterization of performance on a concurrent lever pressing/feeding choice procedure: effects of dopamine antagonist, cholinomimetic, sedative and stimulant drugs. Psychopharmacology, 116, 529-537.

Ettenberg, A. (1989). Dopamine, neuroleptics, and reinforced behavior. Neuroscience and Biobehavior Reviews, 13, 105-111.

Fibiger, H. C., Carter, D. A. \& Phillips, A. G. (1976). Decreased intracranial self-stimulation after neuroleptics or 6-hydroxydopamine: evidence for mediation by reward deficits rather than by reduced reward. Psychopharmacology, 47, 21-27.

Fouriezos, G., Hansson, P. \& Wise, R. A. (1978). Neuroleptic-induce attenuation of brain stimulation reward. Journal of Comparative and Physiological Psychology, 92, 659-669.

Fouriezos, G. \& Wise, R. A. (1976). Pimozide-induce extinction of intracanial self-stimulation: Response patterns rule out motor or performance deficit. Brain Research, 103, 377-380.

Franklin, K. B. J. \& McCoy, S. N. (1979). Pimozideinduced extinction in rats: Stimulus control of 
responding rules out motor deficit. Pharmacology, Biochemistry, and Behavior, 11, 71-76.

Hoebel, B. G. (1988). Neuroscience and motivation: pathways and peptides that define motivational systems. In R. C. Atkinson, R. J. Herrnstein, G. Lindzey, \& R. C. Luce (Eds.), Stevens' Handbook of Experimental Psychology (Vol.1, pp. 527-625). New York: Wiley.

Koch, M., Schmid, A. \& Schnitzler, H. U. (2000). Role of nucleus accumbens dopamine $\mathrm{D} 1$ and $\mathrm{D} 2$ receptors in instrumental and Pavlovian paradigms of conditioned reward. Psychopharmacology, 152, 67-73.

Miller, R., Wickens, J. R. \& Beninger, R. J. (1990). Dopamine $\mathrm{D}-1$ and $\mathrm{D}-2$ receptors in relation to reward and performance: A case for the D-1 receptors as a primary site of therapeutic action of neuroleptic drugs. Progress in Neurobiology, 34, 143-183.

Nevin, J. A. (1974). Response strength in multiple schedules. Journal of the Experimental Analysis of Behavior, 21, 389-408.

Nevin, J. A., Smith, L. D. \& Roberts, J. (1987). Does contingent reinforcement strengthen operant behavior? Journal of the Experimental Analysis of Behavior, 48, 17-33.

Nowen, K. L., Arrizi, M., Carlson, B. B. \& Salamone, J. D. (2001). D1 or D1 antagonists in nucleus accumbens core or dorsomedial shell suppresses lever pressing for food but leads to compensatory increase in chow consumption. Pharmacology, Biochemistry, and Behavior, 69, 373-382.

Pitts, S. M. \& Horvitz, J. C. (2000). Similar effects of D1/D2 receptor blockade on feeding and locomotor behavior. Pharmacology, Biochemistry, and Behavior, 65, 433-438.

Rolls, E. T., Rolls, B. J., Kelly, P. H., Shaw, S. G., Wood, R. J. \& Dale, R. (1974). The relative attenuation of self-stimulation, eating and drinking produced by dopamine-receptor blockade. Psychopharmaco$\log y, 5,615-622$.

Rusk, I. N. \& Cooper, S. J. (1994). Parametric studies of selective D1 and D2 antagonists: Effects on appetitive and feeding behavior. Behavioural Pharmacology, 5, 615-622.

Salamone, J. D. (1986). Different effects of haloperidol and extinction on instrumental behavior. Psychopharmacology, 88, 18-23.
Salamone, J. D. (1987). The actions of neuroleptic drugs on appetitive instrumental behavior. In $\mathrm{L}$. L. Iversen, S. D. Iversen \& S. H. Snyder (Eds.), Handbook of Psychopharmacology (pp. 575-608). New York: Plenum Press.

Salamone, J. D. (1988). Dopaminergic involvement in activational aspects of motivation: Effects of haloperidol on scheduled activity, feeding and foraging in rats. Phychobiology, 16, 196-206.

Salamone, J. D. (1991). Behavioral pharmacology of dopamine systems: A new synthesis. In P. Willner \& J. Scheel-Kruger (Eds.), The Mesolimbic Dopamine Systems: From Motivation to Action (pp. 599-613). Cambridge: Cambridge University Press.

Salamone, J. D. (1992). Complex motor and sensoriomotor functions of striatal and accumbens dopamine: Involvement in instrumental behavior processes. Psychopharmacology, 107, 160-174.

Salamone, J. D. (1996). The behavioral neurochemistry of motivation: Methodological and conceptual issues in studies of the dynamic activity of nucleus accumbens dopamine. Journal of Neurosciences Methods, 64, 137-149.

Salomone, J. D., Arizzi, M. N., Sandoval, M. D., Cervone, K. M. \& Aberman, J. E. (2002). Dopamine antagonists alter response allocation but do no suppress appetite for food in rats: Contrast between the effects of SKF 83566, raclopride, and fenfluramine on a concurrent choice task. Psychopharmacology, 160, 371-380.

Salamone, J. D. \& Correa, M. (2002). Motivational views of reinforcement: implications for understanding the behavioral functions of nucleus accumbens dopamine. Behavior Brain Research, 137, 3-25.

Salamone, J. D., Cousing, M. S. \& Bucher, S. (1994). Ahedonia or anergia? Effects of haloperidol and nucleus accumbens dopamine depletion on instrumental response selection in a T-maze cost/benefit procedure. Behavior Brain Research, 65, 221-229.

Salamone, J. D., Cousing, M. S., Maio, C., Champion, M., Turski, T. \& Kovach, J. (1996). Different behavioral effects of haloperidol, clozapine, and thioridazadine in instrumental lever pressing/feeding procedure. Psychopharmacology, 125, 105-112. 
Salamone, J. D., Cousins, M. S. \& Snyder, B. J. (1997). Behavioral functions of nucleus accumbens dopamine: Empirical and conceptual problems with the anhedonia hypothesis. Neuroscience and Biobehavior Reviews, 21, 341-59.

Salamone, J. D., Steinpreis, R. E., McCullough, L. D., Smith, P., Grebel, D. \& Mahan, K. (1991). Haloperidol and nucleus accumbens dopamine depletion suppress lever pressing for food but increase free food consumption in a novel food-choice procedure. Psychopharmacology, 104, 515-521.

Salamone, J. D., Zigmond, M. J. \& Stricker, E. M. (1990). Characterization of the impaired feeding behavior in rats given haloperidol or dopaminedepleting brain lesions. Neurosciences, 39, 17-24.

Smith, G. P. (1995). Dopamine and food reward. Progress in Psychobiology Physiology and Psychology, 16, 83-144.

Tombaugh, T. N., Tombaugh, J. \& Anisman, H. (1979). Effects of dopamine receptor blockade on alimentary behaviors: Home cage food consumption, magazine training, operant acquisition, and performance. Psychopharmacology, 66, 219-225.

Weatherly, J. N., Arthur, E. I. L. \& Tischart, L. M. (2003). Altering "motivational" variables alters induction produced by upcoming food-pellet reinforcement. Animal Cognition, 6, 17-26.

Weatherly, J. N., Davis, C. S. \& Melville, C. L. (2000). Induction with upcoming food-pellet reinforcement. Learning and Motivation, 31, 180-199.

Weatherly, J. N. \& Moulton, P. L. (2001). The effect of food-pellet reinforcement on rats' rates of lever pressing for $1 \%$ sucrose reinforcers across several "contrast " procedures. Learning and Motivation, 32, 193-218.

Weatherly, J. N., Moulton, P. L. \& Ritt, J. J. (2002). Rats' response rates for $1 \%$ sucrose when food-pellet reinforcement is upcoming: Effects of upcoming reinforcement contingency. Psychological Record, 52, 221-240.

Weatherly, J. N., Rue, H. C., Davis, C. S. \& Melville, C. L. (2000). Delivering different reinforcers in each half of the session: Effect of reinforcement rate. Psychological Record, 50, 543-556.

Weatherly, J. N., Stout, J. E., Davis, C. S. \& Melville, C. L. (2001). For better or worse: Effect of upcoming reinforcer type on rats' lever pressing for low concentration sucrose reinforcers. Psychological Record, 51, 629-644.

Weatherly, J. N., Stout, J. E., McMurry, A. S., Rue, H. C. \& Melville, C. L. (1999). Within-session responding when different reinforcers are delivered in each half of the session. Behavioural Processes, 46, 227-243.

Weatherly, J. N., Stout, J. E., Rue, H. C. \& Melville, C. L. (2000). The effect of second-half reinforcer type on responding for sucrose in the first half of the session. Behavioural Processes, 49, 43-60.

Wise, R. A. (1982). Neuroleptics and operant behavior: The anhedonia hypothesis. Behavioral and Brain Sciences, 5, 39-88.

Wise, R. A. (1985). The anhedonia hypothesis: Mark III. Beh. Brain Sci., 8, 178-186.

Wise, R. A. \& Colle, L. M. (1984). Pimozide attenuates free feeding: best score analysis reveals a motivational deficit. Psychopharmacology, 84, 446-451.

Wise, R. A. \& Raptis, L. (1986). Effects of naloxone and primozide on initiation and maintenance measures of free feeding. Brain Research, 368, 62-68.

Wise, R. A., Spindler, J., de Wit, H. \& Gerberg, G. J. (1978). Neuroleptic-induce "anhedonia" in rats: Pimozide blocks reward quality of food. Science, 201 (4352), 262-264. 
